\section{Stroke}

JOURNAL OF THE AMERICAN HEART ASSOCIATION

\section{American Stroke Association $_{\mathrm{su}}$}

A Division of American Heart Association

\title{
Clinical Outcome After First and Recurrent Hemorrhage in Patients With Untreated Brain Arteriovenous Malformation
}

Jae H. Choi, Henning Mast, Robert R. Sciacca, Andreas Hartmann, Alexander V. Khaw, Jay P. Mohr, Ralph L. Sacco and Christian Stapf

Stroke 2006;37;1243-1247; originally published online Apr 13, 2006;

DOI: 10.1161/01.STR.0000217970.18319.7d

Stroke is published by the American Heart Association. 7272 Greenville Avenue, Dallas, TX 72514

Copyright (C 2006 American Heart Association. All rights reserved. Print ISSN: 0039-2499. Online ISSN: $1524-4628$

The online version of this article, along with updated information and services, is located on the World Wide Web at:

http://stroke.ahajournals.org/cgi/content/full/37/5/1243

Subscriptions: Information about subscribing to Stroke is online at

http://stroke.ahajournals.org/subscriptions/

Permissions: Permissions \& Rights Desk, Lippincott Williams \& Wilkins, a division of Wolters Kluwer Health, 351 West Camden Street, Baltimore, MD 21202-2436. Phone: 410-528-4050. Fax: 410-528-8550. E-mail:

journalpermissions@1ww.com

Reprints: Information about reprints can be found online at http://www.lww.com/reprints 


\title{
Clinical Outcome After First and Recurrent Hemorrhage in Patients With Untreated Brain Arteriovenous Malformation
}

\author{
Jae H. Choi, MD; Henning Mast, MD; Robert R. Sciacca, EngScD; Andreas Hartmann, MD; \\ Alexander V. Khaw, MD; Jay P. Mohr, MD; Ralph L. Sacco, MD; Christian Stapf, MD
}

Background and Purpose - The morbidity from spontaneous hemorrhage of untreated brain arteriovenous malformations (AVM) is not well described.

Methods-The 241 consecutive AVM patients (mean age 37 \pm 16 years, 52\% women) from the prospective Columbia AVM Databank initially presenting with hemorrhage were evaluated using the Rankin Scale (RS) and the National Institute of Health Stroke Scale (NIHSS). From the 241 AVM patients, 29 (12\%) had subsequent intracranial hemorrhage during follow-up. For further comparisons, 84 non-AVM patients with intracerebral hemorrhage from the Northern Manhattan Study (NOMAS) served as a control group.

Results-In 241 AVM patients presenting with hemorrhage the median RS was 2 and the median NIHSS was 1 (49\% RS 0 to $1,61 \%$ NIHSS $<2$ ). The median time between hemorrhage and clinical evaluation was 11 days (mean 219 days). Recurrent AVM hemorrhage during follow-up resulted in no significant increase in morbidity (median RS 2, $P=0.004$; median NIHSS 3, $P=0.322$; time between hemorrhage and study evaluation: median 55 days, mean 657 days). Among AVM-hemorrhage subtypes, parenchymatous AVM hemorrhage was associated with higher stroke morbidity (odds ratio, 2.9; $95 \%$ CI, 1.5 to 5.8 for NIHSS $\geq 2$ ) than nonparenchymatous hemorrhages. Parenchymatous AVM hemorrhage had a significantly better outcome (median NIHSS 1) than non-AVM related hemorrhage (median NIHSS 12; $P<0.0001$ ).

Conclusions-Hemorrhage, either at initial presentation or during follow-up of untreated AVM patients appears to carry a lower morbidity than intracranial hemorrhage from other causes. These findings support a careful weighing of risks from interventional treatment and natural history. (Stroke. 2006;37:1243-1247.)

Key Words: cerebral arteriovenous malformations $\mathbf{~ i n t r a c e r e b r a l ~ h e m o r r h a g e ~} \boldsymbol{~}$ intracranial hemorrhage - outcome — subarachnoid hemorrhage

$\mathrm{U}$ $\mathrm{p}$ to $2 \%$ of all intracranial hemorrhages are caused by ruptured brain arteriovenous malformations (AVM). ${ }^{1,2}$ Despite this small proportion, AVM are gaining more attention because of the more frequent use of noninvasive imaging methods, like brain MRI, which is uncovering an increasing number of such malformations, bled and unbled. ${ }^{3}$ Populationbased studies reveal that about $35 \%$ to $50 \%$ of patients with AVM initially present with hemorrhage, and the annual risk of further hemorrhage may vary from $1 \%$ to $18 \% .^{1,4-9}$ Modern invasive treatment methods have been developed with the aim at eliminating this source of hemorrhage, comprising microsurgical resection, endovascular embolization, radiotherapy, alone or in combination. ${ }^{10}$ However, the risk of invasive therapy needs to be weighed against the natural history hazard of untreated AVM. Although intracranial hemorrhage is generally considered to constitute a possibly devastating event, prior series suggest that AVM hemorrhage may be more benign than previously assumed. ${ }^{11-17}$
To address this issue, we sought to determine the short- and the long-term neurological outcome in patients with untreated AVM after first and recurrent hemorrhage and to compare their outcome with a control sample of non-AVM-related intracerebral hemorrhage cases.

\section{Patients and Methods}

The Columbia University Medical Center is a tertiary referral center recruiting patients with AVM from the local New York Metropolitan area and distant referral sites. The Columbia AVM Database is an ongoing prospective study project with consecutive enrollment since 1989. The aim of this observational study is to collect demographic, clinical, morphological, and treatment data of patients with AVM admitted to our center for diagnosis and treatment. All AVM have been diagnosed based on brain imaging and cerebral angiography. The Columbia AVM Databank design conforms to the national consensus recommendations for AVM research reporting terminology and have been described in prior publications. ${ }^{8,15,16,17}$ This analysis includes patients enrolled in the Columbia AVM Database until August 2004.

Received October 27, 2005; final revision accepted December 30, 2005; accepted February 9, 2006.

From the Stroke Center, The Neurological Institute (J.H.C., H.M., R.R.S, A.H., A.V.K., J.P.M., R.L.S., C.S.), New York-Presbyterian Hospital, Columbia University Medical Center, New York, NY; the Department of Neurology, Ernst Moritz Arndt University, Greifswald (A.V.K.), and Bergmannstrost, Halle, Germany (J.H.C., H.M.); the Department of Neurology, Hôpital Lariboisière, AP-HP, Paris, France (C.S.); and the Division of Stroke Medicine (H.M.), Nottingham, UK.

Correspondence to Jae H. Choi, MD, Stroke Center/The Neurological Institute, NI-614, New York-Presbyterian Hospital, Columbia University Medical Center, 710 West 168th Street, New York, NY 10032, USA. E-mail jchoi@neuro.columbia.edu

(C) 2006 American Heart Association, Inc. 
Hemorrhagic AVM presentation was defined as a symptomatic clinical event with signs of fresh intracranial blood on head CT or MRI or in the cerebrospinal fluid, leading to the diagnosis of a AVM. Recurrent hemorrhage was defined as a new symptomatic follow-up event attributable to AVM rupture, confirmed by brain imaging.

Morphological variables were grouped into AVM location (lobar, deep, infratentorial, and borderzone), drainage pattern (drainage into superficial veins, combined drainage into deep and superficial veins, or into deep veins only), and AVM size (in mm). Concurrent arterial aneurysms were defined as saccular dilatations of the lumen $\geq 2$ times the width of the arterial vessel that carried the dilatation. They were further classified as feeding artery aneurysms, intranidal aneurysms (both considered AVM-associated), and aneurysms unrelated to blood flow to the AVM (nonassociated aneurysms). ${ }^{18}$ Infundibula, arterial ectasias (ie, dilated feeding vessels), and intranidal aneurysmal dilatations seen during the venous angiographic phase only were not coded as arterial aneurysms. Arterial aneurysms were coded as unrelated to the AVM when located on intracranial arteries not contributing blood flow to the malformation.

Hemorrhagic stroke severity and clinical outcome after each hemorrhagic event were measured using the National Institute of Health Stroke Scale (NIHSS) and Rankin Scale (RS). In our analysis, clinical assessment was stratified into favorable (NIHSS score 0 to 1 ) and unfavorable (NIHSS score $\geq 2$ ) neurological outcome.

After the initial hemorrhagic event, only untreated patients were included in the analysis. Follow-up data after hemorrhage as well as the last available data before lesion-targeted treatment were evaluated. Patients were censored at initiation of treatment aiming at AVM obliteration or elimination (date of first embolization, radiotherapy, or surgery).

Predominant anatomical bleeding location, categorized into nonparenchymatous (subarachnoid or ventricular) or parenchymatous hemorrhage, was further tested for its effect on outcome severity.

In addition, outcome after parenchymatous AVM bleeds was compared with outcome data of survivors after non-AVM-related intracerebral hemorrhages from the Northern Manhattan Study (NOMAS) incidence dataset. ${ }^{19}$ NOMAS is a prospective, population-based epidemiological study in a multiethnic population and aims at determining stroke incidence, risk factors for stroke, and functional outcome. All NOMAS patients were evaluated within 30 days after incident intracerebral hemorrhages. For direct outcome comparisons, we included only AVM patients with parenchymatous hemorrhages and documented neurological assessment within 30 days after the index event.

Univariate statistical models were applied to test the effect of hemorrhage location on outcome severity (Wilcoxon Rank Sum test and $\chi^{2}$ test/Fisher exact test). Outcome comparisons between incident and recurrent AVM hemorrhage, and between the Columbia AVM Database and the NOMAS cohort were analyzed using the Wilcoxon Rank Sum test and Two Sample test, and $\chi^{2}$ test/Fisher exact test (level of significance $\alpha=0.05$, respectively). A multivariate logistic regression model was used to test the effect of demographic factors, AVM size, and hemorrhage location on neurological outcome in patients with early outcome assessment ( $\leq 30$ days after the index event).

\section{Results}

\section{Clinical Outcome After Incident AVM Hemorrhage in Untreated AVM Patients}

Overall, 241 AVM patients were clinically evaluated after the hemorrhage event by an independent study neurologist. Baseline characteristics of the study cohort are shown in Table 1.

RS scores were available for all 241 patients, NIHSS scores for 233. The median delay between AVM rupture and initial neurological assessment was 11 days (mean 219 days). Outcome
TABLE 1. Demographic and Morphological Characteristics of 241 Untreated AVM Patients With Hemorrhage at Initial Presentation

\begin{tabular}{lc} 
& \\
\hline Age, mean \pm SD $(\mathrm{y})$ & $37 \pm 16$ \\
Female gender & $125(52 \%)$ \\
Max AVM diameter, mean \pm SD $(\mathrm{mm})$ & $26.4 \pm 15.5$ \\
Location & \\
Lobar & $171(71 \%)^{\star}$ \\
Deep & $46(19 \%)$ \\
Infratentorial & $41(17 \%)$ \\
Borderzone & $70(29 \%)$ \\
Drainage & \\
Superficial & $102(42 \%)$ \\
Deep and superficial & $62(26 \%)$ \\
Deep only & $77(32 \%)$ \\
Aneurysm & \\
Any intracranial & $75(31 \%)$ \\
Flow-related & $46(19 \%)$ \\
Intranidal & $22(9 \%)$ \\
Hemorrhage location & \\
Parenchymatous & $171(71 \%)$ \\
Subarachnoid & $36(15 \%)$ \\
Ventricular & $34(14 \%)$ \\
\hline
\end{tabular}

${ }^{*}$ Total No. exceeds $\mathrm{n}=241$ attributable to overlapping lobar and deep AVM topography in $17(7 \%)$ cases.

results are summarized in Table 2: 119 patients (49\%) had RS scores $\leq 1$ and 34 patients (14\%) had RS scores of 4 or $5 ; 142$ patients $(61 \%)$ were ranked at NIHSS scores of 0 to 1 and 11 patients $(5 \%)>13$. Parenchymatous AVM hemorrhage resulted in significantly higher NIHSS scores than subarachnoid or intraventricular hemorrhage $(P=0.001)$, whereas no significant differences were seen for RS score comparisons (Table 3). By multivariate testing, parenchymatous AVM hemorrhage was an independent predictor for unfavorable outcome (NIHSS score $\geq 2$; Table 4), whereas age, gender, race, and AVM size showed no significant effect.

\section{Clinical Outcome After Follow-Up AVM Hemorrhage in Untreated AVM Patients}

During natural history follow-up (median 55 days, mean 657 days) subsequent AVM hemorrhage occurred in 29 patients (12\%). Neurological outcome as measured by the NIHSS was

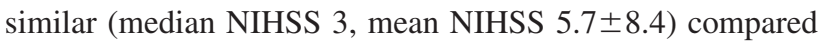
with the incident hemorrhage event (median NIHSS 1, mean NIHSS $3.6 \pm 6.2 ; P=0.322$ ), but disability measured by the RS was worse (follow-up hemorrhage: median RS 2, mean RS 2.7 \pm 1.4 ; incident hemorrhage: median RS 2, mean RS $2.0 \pm 1.4 ; P=0.004)$. One patient died after the recurrent bleed. Clinical improvement after first or recurrent hemorrhage over time was observed in $40 \%$ and $39 \%$ (worsening in $2 \%$ and $4 \%$ ) measured by RS score and by NIHSS subcategories, respectively. 
TABLE 2. Incident and Recurrent AVM Hemorrhage in Untreated AVM Patients

\begin{tabular}{|c|c|c|c|}
\hline RS & $\begin{array}{c}\text { Incident } \\
\text { Hemorrhage }\end{array}$ & $\begin{array}{l}\text { Subgroup of the } \\
\text { Columbia Cohort With } \\
\text { 30-Day Evaluation }\end{array}$ & $\begin{array}{l}\text { Recurrent } \\
\text { Hemorrhage }\end{array}$ \\
\hline Mean \pm SD & $2 \pm 1.4$ & $2 \pm 1.5$ & $2.7 \pm 1.4$ \\
\hline \multirow[t]{2}{*}{ Median } & 2 & 2 & 2 \\
\hline & $\mathrm{n}(\%)$ & n (\%) & n (\%) \\
\hline 0 & $42(17 \%)$ & 25 (16\%) & 0 \\
\hline 1 & 77 (32\%) & $39(24 \%)$ & $7(24 \%)$ \\
\hline 2 & $56(23 \%)$ & $44(28 \%)$ & $9(31 \%)$ \\
\hline 3 & $32(13 \%)$ & $20(13 \%)$ & $6(21 \%)$ \\
\hline 4 & $17(7 \%)$ & $16(10 \%)$ & $3(10 \%)$ \\
\hline 5 & $17(7 \%)$ & $16(10 \%)$ & $4(14 \%)$ \\
\hline Total & $241(100 \%)$ & $160(100 \%)$ & $29(100 \%)$ \\
\hline \multicolumn{4}{|l|}{ NIHSS } \\
\hline Mean $\pm S D$ & $3.6 \pm 6.2$ & $3.6 \pm 6.3$ & $5.7 \pm 8.4$ \\
\hline \multirow[t]{2}{*}{ Median } & 1 & 1 & 3 \\
\hline & n (\%) & n (\%) & $\mathrm{n}(\%)$ \\
\hline 0 to 1 & $142(61 \%)$ & 87 (57\%) & $9(31 \%)$ \\
\hline 2 to 3 & $39(17 \%)$ & $23(15 \%)$ & $6(21 \%)$ \\
\hline 4 to 5 & $16(7 \%)$ & $12(8 \%)$ & $4(14 \%)$ \\
\hline 6 to 7 & $9(4 \%)$ & $8(5 \%)$ & $3(10 \%)$ \\
\hline 8 to 9 & $8(3 \%)$ & $6(4 \%)$ & $2(7 \%)$ \\
\hline 10 to 11 & $6(2 \%)$ & $5(3 \%)$ & $1(3 \%)$ \\
\hline 12 to 13 & $2(1 \%)$ & $5(3 \%)$ & $1(3 \%)$ \\
\hline$>13$ & $11(5 \%)$ & $12(8 \%)$ & $3(10 \%)$ \\
\hline Missing & $8(3 \%)$ & $2(1 \%)$ & \\
\hline Total & $241(100 \%)$ & 160 (100\%) & $29(100 \%)$ \\
\hline
\end{tabular}

\section{Comparison of Clinical Outcomes Between}

Parenchymatous AVM Hemorrhage and

Non-AVM-Related Intracranial Hemorrhage

A total of 160 AVM patients (66\%) had their first clinical examination within 30 days after the initial hemorrhagic event (median delay time 3 days, mean 7 days; Table 2) with a median RS score of 2 (mean $2 \pm 1.5$ ) and a median NIHSS
TABLE 4. Multiple Logistic Regression Model* Testing the Effect of Age, Gender, Race/Ethnicity, AVM Diameter, and Parenchymatous Hemorrhage Location on Unfavorable Outcome (NIHSS $\geq 2$ ) in $n=241$ Patients With AVM-Hemorrhage

\begin{tabular}{lcc}
\hline & Odds Ratio & $95 \% \mathrm{Cl}$ \\
\hline Age (y) & 1.0 & 0.98 to 1.02 \\
Female gender & 0.9 & 0.53 to 1.61 \\
Race/ethnicity (white) & 1.1 & 0.78 to 1.43 \\
Max AVM diameter (mm) & 1.0 & 0.99 to 1.05 \\
Parenchymatous hemorrhage & $2.9 \dagger$ & 1.53 to 5.82 \\
\hline
\end{tabular}

*Interaction terms included in the model are not significant: age-female; age-race; diameter-age; par_hem-age; par_hem-female; par_hem-race; par_hem-diameter. $\dagger P<0.005$.

score of 1 (mean 3.6 \pm 6.3 ). Among these 160 patients, 114 (71\%) experienced parenchymatous AVM hemorrhage and were compared with the 84 survivors of non-AVM-related intracerebral hemorrhage from NOMAS. By univariate comparison, AVM patients were significantly younger, more likely to be of white origin, and showed significantly better clinical outcome (median NIHSS 1 ) than the NOMAS patients (median NIHSS 12; $P<0.0001$; Table 5).

\section{Discussion}

Intracranial hemorrhage constitutes the most feared complication of AVMs and has been considered to carry a high burden of morbidity and mortality. A longitudinal series from Finland, conducted before the modern imaging era, found that $23 \%$ of 166 untreated patients experienced major morbidity or death from AVM hemorrhage. ${ }^{14}$ In a retrospective single center study published in 1984, Fults and Kelly observed 83 AVM patients during a mean follow-up time of 8.7 years, including $62 \%$ who presented with hemorrhage; of the latter, $40.5 \%$ died during follow-up because of the initial or recurrent bleeding. ${ }^{11}$ In a retrospective population-based study by Brown et al, the $168 \mathrm{AVM}$ patients included showed a $2.25 \%$ annual hemorrhage rate with an associated mortality of $29 \%$; the risk of severe disability among hemorrhage survivors was $23 \% .{ }^{13}$ A mixed retrospective and prospective study of 240 AVM patients from Australia suggested $24.6 \%$ of conserva-

TABLE 3. Effect of Anatomic Bleeding Location on Outcome After Hemorrhagic AVM Presentation in Untreated AVM Patients and for the Subgroup With 30-Day Evaluation

\begin{tabular}{lcccccc}
\hline & \multicolumn{2}{c}{ Entire Columbia AVM-Cohort } & \multicolumn{2}{c}{ Subgroup of the Columbia AVM-Cohort With } \\
& $\mathrm{n}(\%)$ & Mean $\pm \mathrm{SD}^{*}$ & Median & $\mathrm{n}(\%)$ & Mean \pm SD $\ddagger$ & Median \\
RS & $30(12 \%)$ & $1.4 \pm 1.1$ & 1 & $16(10 \%)$ & $1.4 \pm 1.1$ & 1 \\
Ventricular & $170(71 \%)$ & $1.9 \pm 1.4$ & 2 & $114(71 \%)$ & $2.1 \pm 1.5$ & 2 \\
Parenchymatous & $32(13 \%)$ & $1.9 \pm 1.6$ & 1 & $25(16 \%)$ & $2.1 \pm 1.7$ & 1 \\
Subarachnoid & $\mathrm{n}(\%)$ & Mean $\pm \mathrm{SD} \dagger$ & Median & $\mathrm{n}(\%)$ & Mean $\pm \mathrm{SD} \S$ & Median \\
NIHSS & $30(13 \%)$ & $0.7 \pm 1.2 \dagger$ & 0 & $16(10 \%)$ & $0.5 \pm 0.9 \dagger$ & 0 \\
Ventricular & $163(70 \%)$ & $3.4 \pm 5.8 \dagger$ & 1 & $114(71 \%)$ & $3.9 \pm 6.1 \dagger$ & 1 \\
Parenchymatous & $32(14 \%)$ & $2.6 \pm 6.3 \dagger$ & 1 & $25(16 \%)$ & $3.5 \pm 7.1 \dagger$ & 1 \\
Subarachnoid & & & & & & \\
\hline
\end{tabular}

Kruskal-Wallis Test: ${ }^{*} P=0.304 ; \dagger P=0.001 ; \ddagger P=0.242 ; \S P=0.01$.

For the NIHSS, data only from 233 patients were available. For patients with undetermined bleeding location $(n=9)$ no RS or NIHSS scores are given. 
TABLE 5. Comparison of Demographic and Clinical Characteristics in Patients After AVM- and Non-AVM-Related Parenchymatous Hemorrhage (Clinical Assessment $\leq 30$ Days After Index Event)

\begin{tabular}{lccc}
\hline & $\begin{array}{c}\text { AVM-related } \\
\text { Parenchymatous } \\
\text { Hemorrhage } \\
\mathrm{n}=114\end{array}$ & $\begin{array}{c}\text { Non AVM-related } \\
\text { Parenchymatous } \\
\text { Hemorrhage } \\
\mathrm{n}=84\end{array}$ & $P$ \\
\hline Age, mean (SD) & $35(15)$ & $65(15)$ & $<0.0001^{*}$ \\
Female gender & $54(47 \%)$ & $46(55 \%)$ & $0.304 \dagger$ \\
Race/ethnicity & & $20(24 \%)$ & $<0.001 \dagger$ \\
White & $78(68 \%)$ & $21(25 \%)$ & \\
Black & $7(6 \%)$ & $43(51 \%)$ & \\
Hispanic & $23(20 \%)$ & 0 & $<0.0001^{*}$ \\
Asian & $6(5 \%)$ & $13.6 \pm 9.5$ & $<0.0001$ \\
Outcome (NIHSS) & & 12 & \\
Mean \pm SD & $3.9 \pm 6.2$ & $20(24 \%)$ & \\
Median & 1 & $28(33 \%)$ & $<0.0001 \dagger$ \\
0 to 5 & $83(73 \%)$ & $36(43 \%)$ & \\
6 to 13 & $19(17 \%)$ & & \\
$>13$ & $6(5 \%)$ & & \\
\hline
\end{tabular}

*Wilcoxon Two Sample test; $\dagger \chi^{2}$ test.

For 6 (5\%) AVM patients no NIHSS scores were available.

tively managed patients die of AVM hemorrhage within an average of 10 years from diagnosis, and $27 \%$ of the survivors remained severely disabled (RS score $\geq 3$ ). ${ }^{5}$ Finally, a recent retrospective analysis of hospital discharge data suggested $33 \%$ of patients experiencing AVM hemorrhage had major neurological impairment with a RS score $\geq 3 .{ }^{20}$

In contrast to the figure cited above, a few prior series suggested that outcome after AVM rupture might actually be more benign: in a retrospective analysis, Crawford et al reported an overall mortality rate of $1.5 \%$ per year $(1.6 \%$ for those after initial hemorrhage) and an annual rate of severe morbidity of $1.4 \% .^{12}$ In a previous smaller patient sample from the Columbia AVM Database (115 patients after AVM hemorrhage with neurological assessment, mean follow-up time 1.35 years) only $7 \%$ were assigned RS scores of 4 or 5 after first and subsequent bleeding event. ${ }^{17}$ The proportion of asymptomatic patients (RS 0) was $47 \%$, an additional $37 \%$ remained independent in their daily activities (RS 1).

Our own findings argue in favor of a relatively low morbidity after incident AVM hemorrhage with an average RS score of 2 at the time of the initial AVM rupture. Further, neurological impairment was mainly determined by parenchymatous AVM bleeding with an almost 3-fold increased risk for unfavorable outcome compared with nonparenchymatous hemorrhage. However, when compared with patients after non-AVM-related intracerebral hemorrhage, AVM patients with intraparenchymatous bleeding still had significantly better outcomes. ${ }^{21,22,23}$

Twelve percent of our untreated patients experienced recurrent AVM hemorrhage during an average follow-up of 1.8 years, leading to a crude annual rebleeding rate of $7 \%$. This supports prior findings showing relatively high rerupture rates in patients after hemorrhagic AVM presentation, espe- cially during the first year after the index event. ${ }^{16,20}$ However, in our sample recurrent AVM hemorrhage did not alter clinical outcome and carried a low mortality.

The outcome comparison between the Columbia AVM Database and the NOMAS incidence cohort carries some methodological limitations: the majority of cases in NOMAS were evaluated within the first 3 days after their stroke. With an average delay of 7 days (median 3 days) between index event and first clinical assessment for the AVM cohort, we cannot exclude the possibility of a systematic bias. Whereas AVM (ruptured and unruptured) are mainly found in a relatively young population (3rd decade of life), subarachnoid hemorrhage and non-AVM-related intracerebral hemorrhage (4th/5th decade and older) occur in a significantly older population. Also, the distribution of gender and risk factors for hemorrhage differ between those entities. Table 5 summarizes further demographic differences between the 2 study samples: the mean age of the NOMAS-cohort was significantly higher $(65 \pm 15$ versus $37 \pm 16 ; P<0.0001)$ and the proportion of nonwhite individuals was significantly higher in the NOMAS cohort (76\% versus $30 \% ; P<0.0001)$. Although the effect of race/ethnicity on AVM natural history remains as yet unknown, ${ }^{10}$ the significantly younger age among AVM patients may act as a confounder when comparing outcome with non-AVM-related hemorrhage. Also, comorbidity was not systematically coded in the Columbia AVM Databank; hence, no further baseline comparisons with the more elderly NOMAS cohort could be undertaken.

The AVM patient sample is drawn from a large prospective dataset, but attributable to as yet unknown population-based case fatality rates after AVM hemorrhage, referral center cohorts such as ours may underestimate the overall frequency of incident AVM hemorrhage and associated risk factors. ${ }^{1,4}$ In addition, referral bias to specialized treatment centers may influence demographic and clinical characteristics of local patient cohorts. The possibility of systematic or random error in the data analysis can therefore not be excluded and our results will need confirmation from the currently ongoing population-based studies. ${ }^{8,7}$

Prior studies have generally not included report on the delay of clinical assessment after the bleeding event. The timedependent inclusion criteria as used in our analysis (neurological evaluation within 30 days after the index event) is more likely to reveal the actual impact of hemorrhage after AVM rupture. The results of the present study support assumptions, that not only the course, but also the clinical presentation after hemorrhages attributable to AVM-rupture seem to be milder when compared with non-AVM-related intracerebral hemorrhage. This effect may be explained in part by the relatively younger age, different premorbid characteristics, lower AVM leakage pressure and bleeding into the AVM nidus itself without major disruption of actual brain tissue.

\section{Acknowledgments}

This study was supported by grants from the National Institute of Neurological Disorders and Stroke R01 NS 40792-01 (Principal Investigator: J.P.M.), NS 29993 (Principal Investigator: R.L.S.), and the Agoston Foundation (J.H.C.). The authors thank Steven Marshall for his reliable help during the data collection process. 


\section{References}

1. Stapf C, Labovitz DL, Sciacca RR, Mast H, Mohr JP, Sacco RL. Incidence of adult brain arteriovenous malformation haemorrhage in a prospective population-based stroke survey. Cerebrovasc Dis. 2002;13: 43-46.

2. Perret G, Nishioka H. Report on the cooperative study of intracranial aneurysms and subarachnoid haemorrhage. Section VI. Arteriovenous malformations An analysis of 545 cases of cranio-cerebral arteriovenous malformations and fistulae reported to the cooperative study. $\mathrm{J} \mathrm{Neu}$ rosurg. 1966;25:467-490.

3. Brown RD, Flemming KD, Meyer FB, Cloft HJ, Pollock BE, Link ML. Natural history, evaluation, and management of intracranial vascular malformations. Mayo Clin Proc. 2005;80:269-281.

4. Brown RD Jr, Wiebers DO, Torner JC, O'Fallon WM. Incidence and prevalence of intracranial vascular malformations in Olmsted County, Minnesota, 1965 to 1992. Neurology. 1996a;46:949-952.

5. ApSimon HT, Reef H, Phadke RV, Popovic EA. A population-based study of brain arteriovenous malformation. Long-term treatment outcomes. Stroke. 2002;33:2794-2800.

6. Hillman J. Population-based analysis of arteriovenous malformation treatment. J Neurosurg. 2001;95:633-637.

7. Al-Shahi R, Bhattacharya JJ, Currie DG, Papanastassiou V, Ritchie V, Roberts R, Sellar RJ, Warlow CP; for the SIVMS Collarborators. Prospective, population-based detection of intracranial vascular malformations in adults. The Scottish Intracranial Vascular Malformation Study (SIVMS). Stroke. 2003;34:1163-1169.

8. Stapf C, Mast H, Sciacca RR, Berenstein A, Nelson PK, Gobin YP, Pile-Spellman J, Mohr JP; for the New York Islands AVM Study Collaborators. The New York Islands AVM Study: Design, Study progress, and initial results. Stroke. 2003;34:e29-e33.

9. Mast H, Young WL, Koennecke HC, Sciacca RR, Osipov A, PileSpellman J, Hacein-Bey L, Duong H, Stein BM, Mohr JP. Risk of spontaneous haemorrhage after diagnosis of cerebral arteriovenous malformation. Lancet. 1997;350:1065-1068.

10. Choi JH, Mohr JP. Brain arteriovenous malformations in adults. Lancet Neurol. 2005;4:299-308.

11. Fults D, Kelly DL Jr. Natural history of arteriovenous malformations of the brain: a clinical study. Neurosurgery. 1984;15:658-662.

12. Crawford P, West CR, Chadwick DW, Shaw MDM. Arteriovenous malformations of the brain: natural history in unoperated patients. $J$ Neurol Neurosurg Psychiatry. 1986;49:1-10.

13. Brown RD, Wiebers DO, Forbes G, O'Fallon WM, Piepgras DG, Marsh WR, Maciunas RJ. The natural history of unruptured intracranial arteriovenous malformations. J Neurosurg. 1988;68:352-357.
14. Ondra SL, Troupp H, George ED, Schwab K. The natural history of symptomatic arteriovenous malformations of the brain: a 24-year follow-up assessment. J Neurosurg. 1990;73:387-391.

15. Joint Writing Group of the Technology Assessment Committee American Society of Interventional and Therapeutic Neuroradiology; Joint Section on Cerebrovascular Neurosurgery a Section of the American Association of Neurological Surgeons and Congress of Neurological Surgeons; Section of Stroke and the Section of Interventional Neurology of the American Academy of Neurology. Reporting Terminology for Brain Arteriovenous Malformation Clinical and Radiographic Features for Use in Clinical Trials. Stroke. 2001;32:1430-1442.

16. Stapf C, Mohr JP. New concepts in adult brain arteriovenous malformations. Curr Opin Neurol. 2000;13:63-67.

17. Hartmann A, Mast H, Mohr JP, Koennecke HC, Osipov A, Pile-Spellman J, Duong DH, Young WL. Morbidity of intracranial haemorrhage in patients with cerebral arteriovenous malformation. Stroke. 1998;29: 931-934.

18. Stapf C, Mohr JP, Pile-Spellman J, Sciacca RR, Hartmann A, Schumacher HC, Mast H. Concurrent arterial aneurysms in brain arteriovenous malformations with hemorrhagic presentation. J Neurol $\mathrm{Neu}$ rosurg Psychiatr. 2002;73:294-298.

19. Sacco RL, Boden-Albala B, Gan R, Chen X, Kargman DE, Shea S, Paik MC, Hauser A; the Northern Manhattan Stroke Study Collaborators. Stroke incidence among white, black, and Hispanic residents of an urban community. Am J Epidemiol. 1998;147:259-268.

20. Halim AX, Johnston SC, Singh V, McCulloch CE, Bennett JP, Achrol AS, Sidney S, Young WL. Longitudinal risk of intracranial hemorrhage in patients with arteriovenous malformation of the brain within a defined population. Stroke. 2004;35:1697-1702.

21. Bamford J, Sandercock P, Dennis M, Burn J, Warlow C. A prospective study of acute cerebrovascular disease in the community: the Oxfordshire Community Stroke Project-1981-86. 2. Incidence, case fatality rates and overall outcome at one year of cerebral infarction, primary intracerebral and subarachnoid haemorrhage. J Neurol Neurosurg Psychiatry. 1990;53:16-22.

22. Thrift AG, Dewey HM, Macdonell RA, McNeil JJ, Donnan GA. Incidence of the major stroke subtypes: initial findings from the North East Melbourne stroke incidence study (NEMESIS). Stroke. 2001;32: 1732-1738.

23. Hanel RA, Xavier AR, Mohammad Y, Kirmani JF, Yahia AM, Qureshi AI. Outcome following intracerebral hemorrhage and subarachnoid hemorrhage. Neurol Res. 2002;24(suppl 1):S58-S62. 